\title{
Binuclear phthalocyanines with aromatic bridges
}

\author{
Herman lam, Sebastian M. Marcuccio, Polina I. Svirskaya, Shafrira Greenrerg, A. B. P. Lever, \\ AND ClifFord C. LEZNOFF ${ }^{i}$ \\ Department of Chemistry, York University, 4700 Keele Street, North York, Ont., Canada M3J IP3 \\ AND \\ RONALD L. CERNY \\ Midwest Center for Mass Spectrometry, University of Nebraska-Lincoln, Lincoln, NE 68558, U.S.A.
}

\begin{abstract}
Herman lam, Sebastian M. Marcuccio, Polina I. Svirskaya, Shafrira Greenberg, A. B. P. Lever, Clifford C. Leznoff, and Ronald L. Cerny. Can. J. Chem. 67, 1087 (1989).

Three different binuclear phthalocyanines were prepared and characterized. Two of the binuclear phthalocyanines are cofacially linked by rigid naphthalene and anthracene spacers, while the third consists of a direct linkage between two phthalocyanine rings. The dicobalt, dicopper, and dizinc derivatives were prepared by inserting the metal into the metal-free species. The synthesis and the physical and spectroscopic properties of the precursor bisphthalonitriles are also included.
\end{abstract}

Key words: phthalocyanines, cofacial, binuclear, bisphthalonitriles.

Herman lam, Sebastian M. Marcuccio, Polina I. Svirskaya, Shafrira Greenberg, A. B. P. Lever, Clifford C. Leznoff et Ronald L. Cerny. Can. J. Chem. 67, 1087 (1989).

On a préparé et caractérisé trois phtalocyanines binucléaires différentes. Deux d'entre elles sont liées d'une façon cofaciale par le biais de noyaux naphtalène et anthracène qui agissent comme rondelle d'espacement; dans le cas de la troisième, i] s'agit d'un lien direct entre deux cycles phtalocyanines. On a préparé les dérivés comportant deux atomes de cobalt, de cuivre ou de zinc en insérant les métaux dans des espèces ne contenant pas de métal. On décrit aussi la synthèse ainsi que les propriétés physiques et spectroscopiques des bisphtalonitriles qui sont les précurseurs des phtalocyanines.

Mots clés : phtalocyanines, cofacial, binucléaire, bisphtalonitriles.

The use of porphyrins and phthalocyanines in electrocatalysis has been the subject of intensive research (1).

Four-electron reductions of oxygen to water using cofacial dicobalt porphyrins have been reported by different groups of researchers $(2,3)$. The cofacial structures have been achieved either by using a cyclophane type of framework (2) or by covalently linking two porphyrins on rigid spacers, via the 1,8-positions of anthracene and biphenylene (3). Some of these binuclear porphyrins are sensitive to light, oxygen, or both (2). To overcome this problem, we have synthesized metal-free binuclear phthalocyanines covalently linked by one (4), two (5), four (5), five (6), and " -1 " (7) atom bridges and some of their metallated derivatives. In general these phthalocyanines are very stable towards light and oxygen. The dicobalt derivatives of these binuclear phthalocyanines catalyze the two-electron reduction of oxygen to hydrogen peroxide but the four-electron process has not been observed (8). The lack of a permanent cofacial interaction between the two phthalocyanine rings may be one of the reasons for not achieving the goal of a fourelectron reduction. We wished to prepare phthalocyanine derivatives analogous to the cofacial porphyrins that catalyze the four-electron reduction of oxygen to water. Methods were developed to link phthalonitrile units to rigid spacer molecules to form the bridging bisnitriles, which can be converted to binuclear phthalocyanines.

We report herein the synthesis of three examples of binuclear phthalocyanines and their dicobalt, dicopper, and dizinc derivatives. In the direct linked binuclear phthalocyanines, the two phthalocyanine rings are joined as two phenyl groups in biphenyl derivatives, while in the cofacial systems the two phthalocyanine rings are linked via the 1,8-positions of naphthalene (9) and anthracene. With these new binuclear phthalocyanines,

\footnotetext{
'Author to whom correspondence may be addressed.
}

we have now synthesized a series of binuclear phthalocyanines in which the covalent bridging linkages range from five to " 1 " atoms.

\section{Synthesis of directly linked binuclear phthalocyanines}

By a previously described method (10), elemental nickel was generated by reduction of nickel iodide with lithium in dry glyme in the presence of naphthalene. The activated nickel powder catalyzed the self-coupling of 4-iodophthalonitrile (1) to give $3,3^{\prime}, 4,4^{\prime}$-tetracyanobiphenyl (2) in $78 \%$ yield. Compound 2 was converted into its 1,3-diiminoisoindoline $(3)(5,6)$. Condensation of 3 with 5-neopentoxy-1,3-diiminoisoindoline (4) $(5,6)$ was carried out in $2-N, N$-dimethylaminoethanol for $36 \mathrm{~h}$. The resulting dark blue solution was purified by flash chromatography (11) to give the mononuclear 2,9,16,23-tetraneopentoxyphthalocyanine (5) and the binuclear 2,2-bi- $(9,16,23-$ trineopentoxyphthalocyanine) $(6 a)$ in 55 and $33 \%$ yield respectively. We can refer to $6 a$ as the zero atom bridged binuclear phthalocyanine. The binuclear phthalocyanine $6 a$ was converted to its dicobalt $6 b$ and dicopper $6 c$ derivatives by refluxing $6 a$ in toluene/2-methoxyethanol with $\mathrm{CoCl}_{2}$ and $\mathrm{Cu}(\mathrm{OAc})_{2}$ respectively $(5,6)$. Compounds 2 and $6 a-c$ were fully characterized by spectroscopic data and elemental analysis (see Experimental). Some spectroscopic data of $6 a$ but not its synthesis or characterization have been previously mentioned (12).

\section{Synthesis of binuclear phthalocyanines covalently bridged by naphthalene}

Treatment of 1 and 1,8-diiodonaphthalene (7) with elemental nickel (10) at room temperature for $3.5 \mathrm{~h}$ gave 1,8 -bis $(3,4-$ dicyanophenyl)naphthalene (8), 1-iodo-8-(3,4-dicyanophenyl)naphthalene (9), and 3,3',4,4'-tetracyanobiphenyl (2) in 15.5, 2.5 , and $42.5 \%$ yield respectively. Compound 8 was converted to its 1,3 -diiminoisoindoline $(\mathbf{1 0})$ as previously described $(5,6)$. 

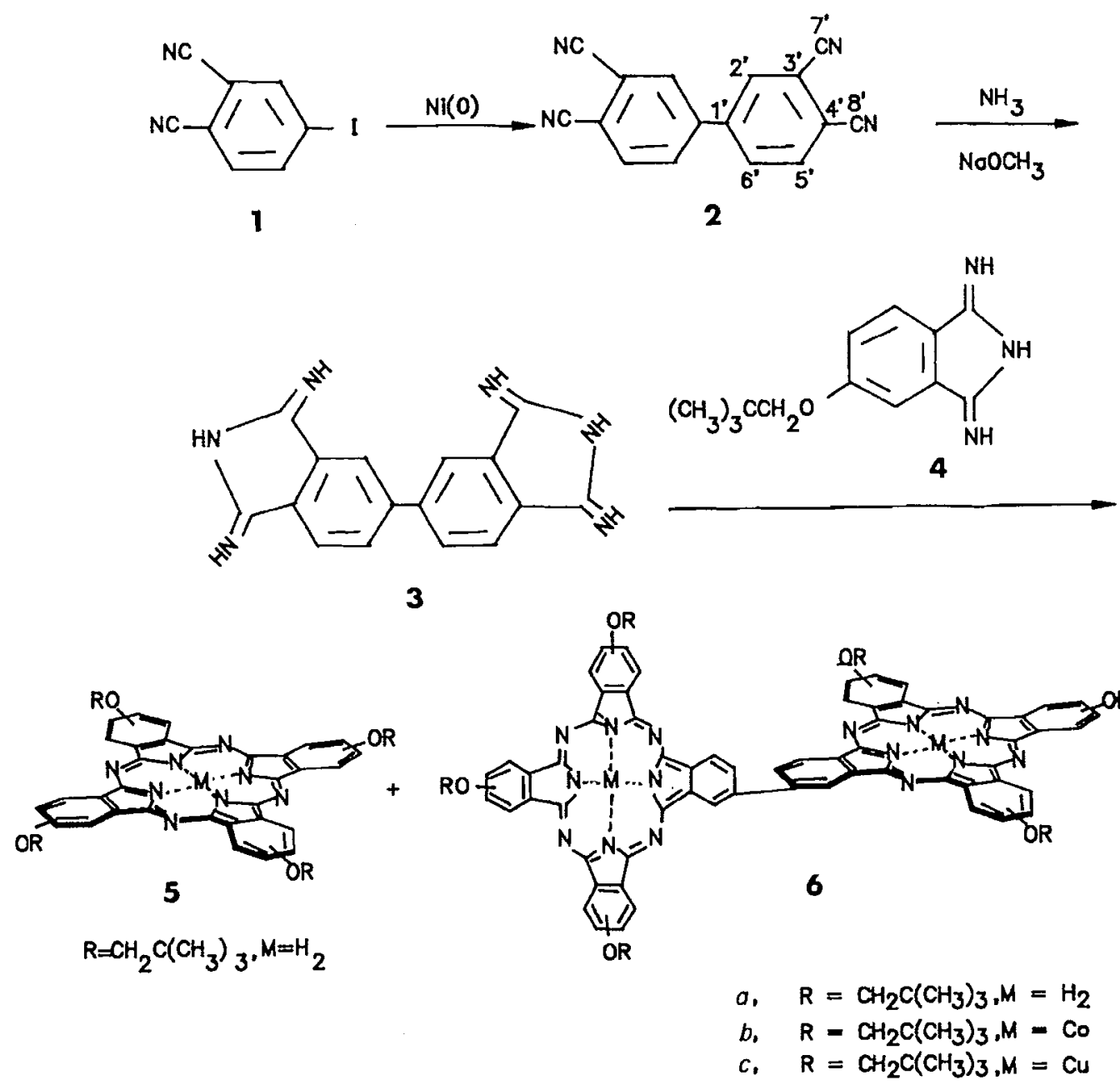

SCHEME 1

Condensation of 10 and 4 in 2-N,N-dimethylaminoethanol for $44 \mathrm{~h}$ gave a dark green solution. Purification by flash chromatography (11) followed by vacuum liquid chromatography (13) gave the mononuclear 5 and the binuclear $11 a$ in 45 and $8.7 \%$ yield respectively. The binuclear $11 a$ was converted to its dicobalt $\mathbf{1 1} b$, dicopper $11 c$, and dizinc $11 d$ derivatives by refluxing $11 a$ in toluene/2-methoxyethanol with $\mathrm{CoCl}_{2}, \mathrm{Cu}(\mathrm{OAc})_{2}$, and $\mathrm{Zn}(\mathrm{OAc})_{2}$ respectively. Although $11 a-d$ and 8 have been reported in a communication (9), the full details are reported here (see Experimental). The binuclear phthalocyanines 11 a-d exhibit parent ion clusters in their fast atom bombardment (FAB) mass spectra (14). More importantly, no evidence of partially or half-metallated species of $11 b-d$ were observed. The ultraviolet-visible (uv) spectrum of $11 a$ gave a single broad (symmetric shape) absorption at the $\mathrm{Q}$ band region that had not been observed before in other metal-free binuclear phthalocyanines $(7,12)$. A more detailed ${ }^{1} \mathrm{H}$ nmr analysis of 8 than previously reported (9) indicates that the compound exists as a mixture of two rotamers at room temperature in a 1:1 ratio. The existence of rotamers suggests that there is a rotation barrier sufficiently higher than that of the unsubstituted 1,8diphenylnaphthalene (15). The ${ }^{13} \mathrm{C}$ nmr of 8 also indicates the presence of rotamers at room temperature.

These rotamers did not separate by chromatographic methods. Although the two rotamers of 8 could be observed on the nmr time scale, their ultimate use in the formation of phthalocya- nines at high temperatures, resulting in their subsequent equilibration again, removed any incentive to resort to heroic efforts to isolate the rotamers of $\mathbf{8}$. After condensation, the binuclear phthalocyanine $11 a$ should also exist as two isomers due to restriction in the rotation of the phthalocyanine rings. The two possible isomers of $11 a$ were isolated as one fraction by chromatography. Construction of molecular models of $11 a$ has shown substantial overlap of the two phthalocyanine rings in each isomer, and this may be the reason that these almost identical isomers are not separable by column chromatography. Separation of these isomers of $11 a$ using high performance liquid chromatography (hplc) on a silica gel column was also not successful.

\section{Synthesis of binuclear phthalocyanines covalently bridged by anthracene}

The coupling reaction of aromatic halides using elemental nickel works well only with reactive halides such as iodides. The 1,8-diiodoanthracene is unknown. Even though 1,8-dichloroanthracene is readily available (16), it is not active enough to undergo the desired cross-coupling reaction.

Less electropositive arylzinc derivatives can tolerate various electrophilic functional groups such as nitriles and esters (17). These organometallic reagents readily undergo cross-coupling reactions with aryl halides (18), making arylzinc derivatives the reagents of choice in our synthesis. In general, direct attack 

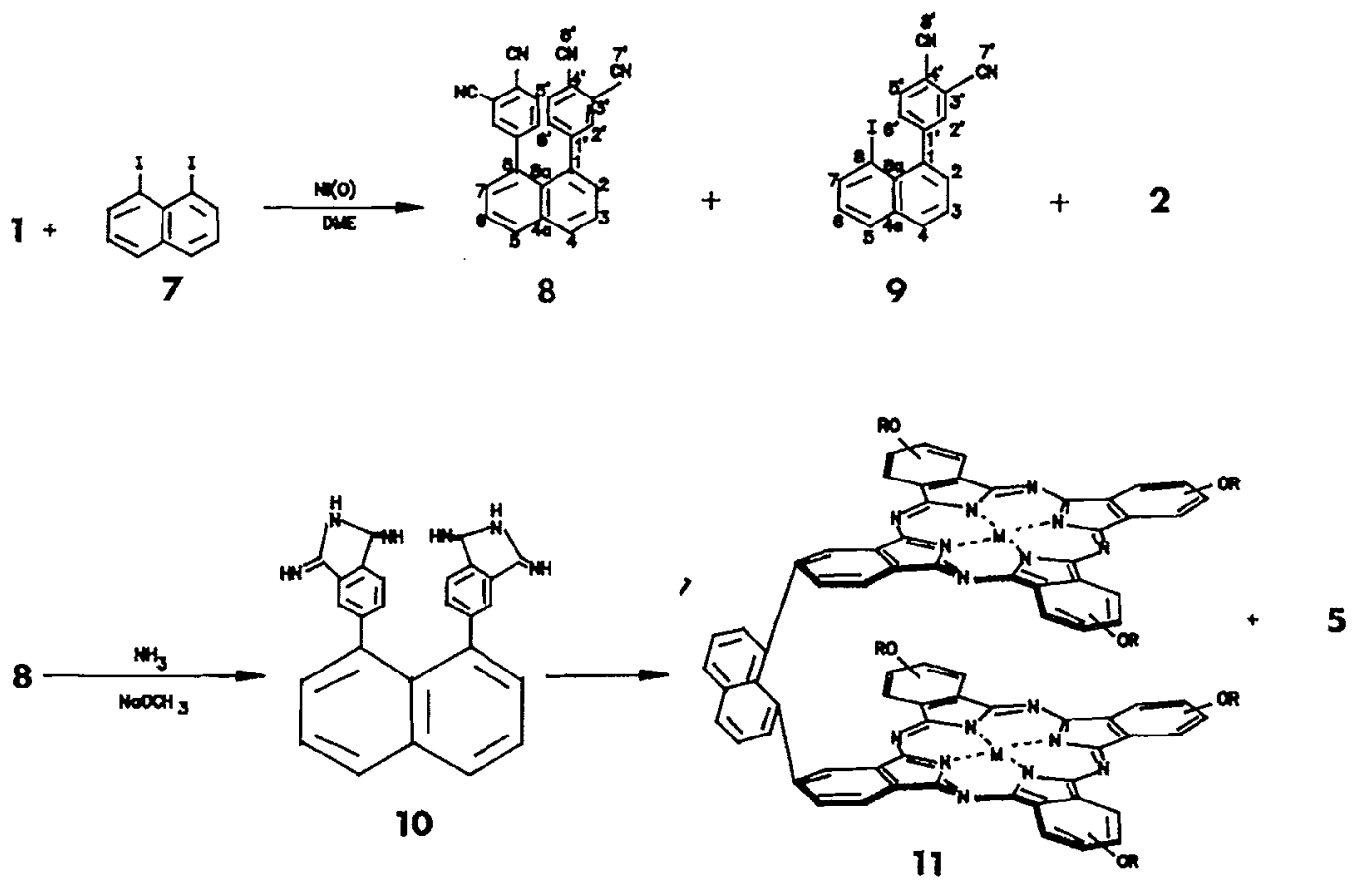

$$
\begin{array}{ll}
a, & \mathrm{R}=\mathrm{CH}_{2} \mathrm{C}\left(\mathrm{CH}_{3}\right)_{3}, M=\mathrm{H}_{2} \\
\text { b. } & \mathrm{R}=\mathrm{CH}_{2} \mathrm{C}\left(\mathrm{CH}_{3}\right)_{3}, \mathrm{M}=\mathrm{Co} \\
\text { c. } & \mathrm{R}=\mathrm{CH}_{2} \mathrm{C}\left(\mathrm{CH}_{3}\right)_{3}, \mathrm{M}=\mathrm{Cu} \\
\text { d. } & \mathrm{R}=\mathrm{CH}_{2} \mathrm{C}\left(\mathrm{CH}_{3}\right)_{3}, \mathrm{M}=\mathrm{Zn}
\end{array}
$$

SCHEME 2

of aryl halide by zinc metal is difficult and the organozinc reagents are usually obtained by a two-step process from organolithium or Grignard reagents and the zinc halides (19). Instead of using an alkyllithium/aryl halide reaction to generate the organolithium intermediate, the organolithium can be generated conveniently by reacting the aryl halide directly with lithium metal in tetrahydrofuran (THF) using ultrasonic irradiation without any noticeable side reaction (20).

Treatment of 1,8-dichloroanthracene (12) with lithium and zinc bromide in dry THF at $0^{\circ} \mathrm{C}$ with ultrasonic activation for $2 \mathrm{~h}$ generated the 1,8-organozinc intermediate (13) (21). A cross-coupling reaction between 1 and 13 catalyzed by tetrakis(triphenylphosphine)palladium $(17,18)$ gave 1,8 -bis $(3,4$ dicyanophenyl)anthracene (14) in $9.9 \%$ yield. Compound 14 was converted to its 1,3-diiminoisoindoline (15) and condensed with 4 in $2-N, N$-dimethylaminoethanol to give a dark green mixture. Upon dilution with water the mixture gave a blue colored residue. The mixture was purified by flash chromatography (11) to give a mixture of mononuclear phthalocyanine 5 and binuclear phthalocyanine $\mathbf{1 6} a$. A trace of the mononuclear phthalocyanine 5 was removed by gel permeation chromatography (22) to give the binuclear $16 a$ in $12 \%$ yield. Metal-free binuclear phthalocyanine $16 a$ was converted to its dicobalt (16b) and dizinc (16c) derivatives by standard procedures.

Unlike 8, bisnitrile 14 does not exist as a mixture of rotamers, as shown by its simpler ${ }^{1} \mathrm{H}$ and ${ }^{13} \mathrm{C}$ nmr spectra, because of the low rotation barrier between the two phenyl rings in the 1,8 anthracene system (23). The uv spectrum of binuclear phthalocyanine $16 a$ exhibits broad symmetric absorption similar to 11a. Parent ions were exhibited in the (FAB) mass spectra of
$16 a-c$ and no evidence for partially metallated species for $16 b$ and $c$ was observed.

Attempts to apply a similar organozinc procedure to $1,8-\mathrm{di}$ iodonaphthalene did not give the desired product $8(17-19)$. The products isolated were found to be 1-(3,4-dicyanophenyl)naphthalene (18) and 2. Due to the close proximity of the 1,8-positions on naphthalene, the formation of a monozincnaphthalene intermediate 17 may be favoured over the naphthalene-1,8-dizinc species, although a dimer of 17 cannot be excluded. Reaction of 1 and 17 with zinc dissociated from naphthalene after reaction may explain the formation of $\mathbf{1 8}$. The elemental nickel used in the cross-coupling reaction is not a true catalyst since it is not regenerated after the reaction (10). Large amounts of nickel iodide (more than $1: 1$ ratio) have been used for satisfactory results. Thin-layer chromatography of the reaction mixture has shown that the cross coupling between the organozinc derivatives and 4-iodophthalonitrile (1) is faster than the homo-coupling of 1 itself. In this regard, the crosscoupling reaction of organometallics and aryl halides catalyzed by transition metal complexes is superior to the mixed coupling between different aryl halides catalyzed by elemental nickel. The cross-coupling product is expected to be the major product in the case of the organometallic/aryl halide reaction, whereas the homo-coupling product is expected to be the major product in the elemental nickel catalyzed aryl halides coupling. The low yield of 1,8-bis(3,4-dicyanophenyl)naphthalene (8) is predictable because the 1,8 -diiodonaphthalene has to react twice with 4-iodophthalonitrile to form the product, and has to compete against the homo-coupling reaction. The poor yield of 1,8-bis(3,4-dicyanophenyl)anthracene, which is obtained via a 


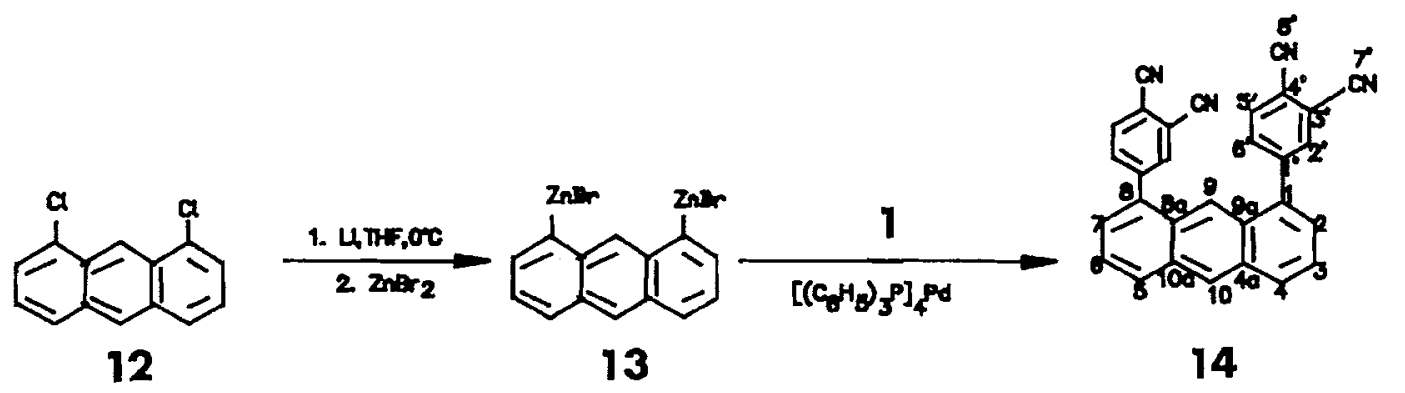

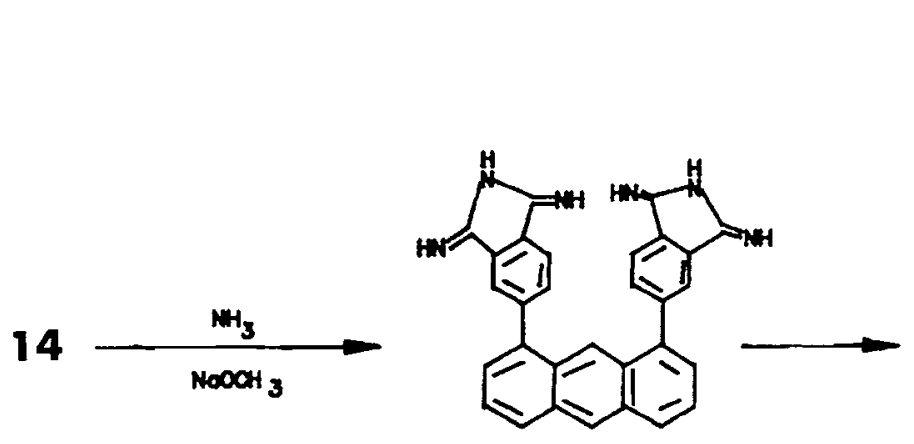

15

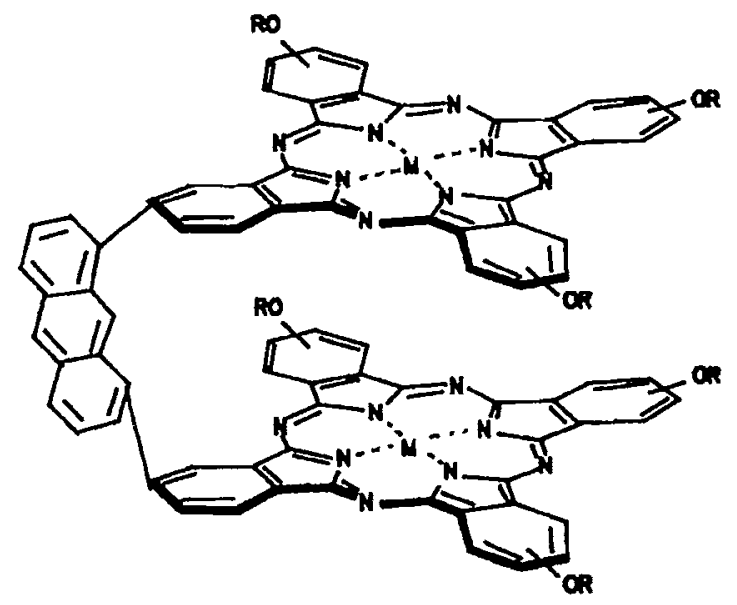

16

$$
\begin{aligned}
& \text { a, } \quad \mathrm{R}=\mathrm{CH}_{2} \mathrm{C}\left(\mathrm{CH}_{3}\right)_{3}, \mathrm{M}=\mathrm{H}_{2} \\
& \text { b. } \quad \mathrm{R}=\mathrm{CH}_{2} \mathrm{C}\left(\mathrm{CH}_{3}\right)_{3}, \mathrm{M}=\mathrm{Co} \\
& \text { c. } \quad \mathrm{R}=\mathrm{CH}_{2} \mathrm{C}\left(\mathrm{CH}_{3}\right)_{3}, \mathrm{M}=\mathrm{Zn}
\end{aligned}
$$

SCHEME 3

different coupling, may be due to incomplete formation of the 1,8-dilithiated intermediate. Half of the 1,8-dichloroanthracene was recovered. Also, the possible formation of polymeric organozinc in which the zinc atom acts as a bridge to link up adjacent anthracene molecules may decrease the yield.

Physical and spectroscopic properties of the phthalonitriles

Phthalonitriles 2, 8, 14, and 18 all have melting points higher than their unsubstituted parent compounds $(16,24)$ and exhibit characteristic CN absorption in the infrared region at $2240 \mathrm{~cm}^{-1}$. Phthalonitriles 8 and 9 have the same molecular weight of 380 . High resolution mass spectra of $\mathbf{8}$ and $\mathbf{9}$ were obtained to check their elemental composition. Together with elemental analysis data, phthalonitrile 8 was clearly identified as the symmetrical 1,8-disubstituted product.

The proton $\mathrm{nmr}$ spectra of the bisphthalonitriles all showed complicated patterns in the aromatic region. Chemical shift assignments were achieved for $2,8,9,14$, and 18 with additional coupling information obtained from correlation $\mathrm{nmr}$ and homo-decoupling experiments (Table 1). Carbon/proton correlation experiments have been done on the more soluble phthalonitriles (Table 2). The ${ }^{1} \mathrm{H} \mathrm{nmr}$ and ${ }^{13} \mathrm{C} \mathrm{nmr}$ of 2 are relatively simple. Selective irradiation of $\mathrm{H}^{\prime}, \mathrm{H}^{\prime}$, and $\mathrm{H}^{\prime}$ in 2 , which resulted in changes in signal intensity in the ${ }^{13} \mathrm{C}$ spectra due to the nOe effect, helps to identify the chemical shifts of the carbons $(26,27)$.
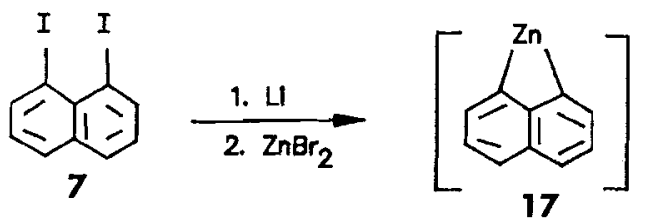

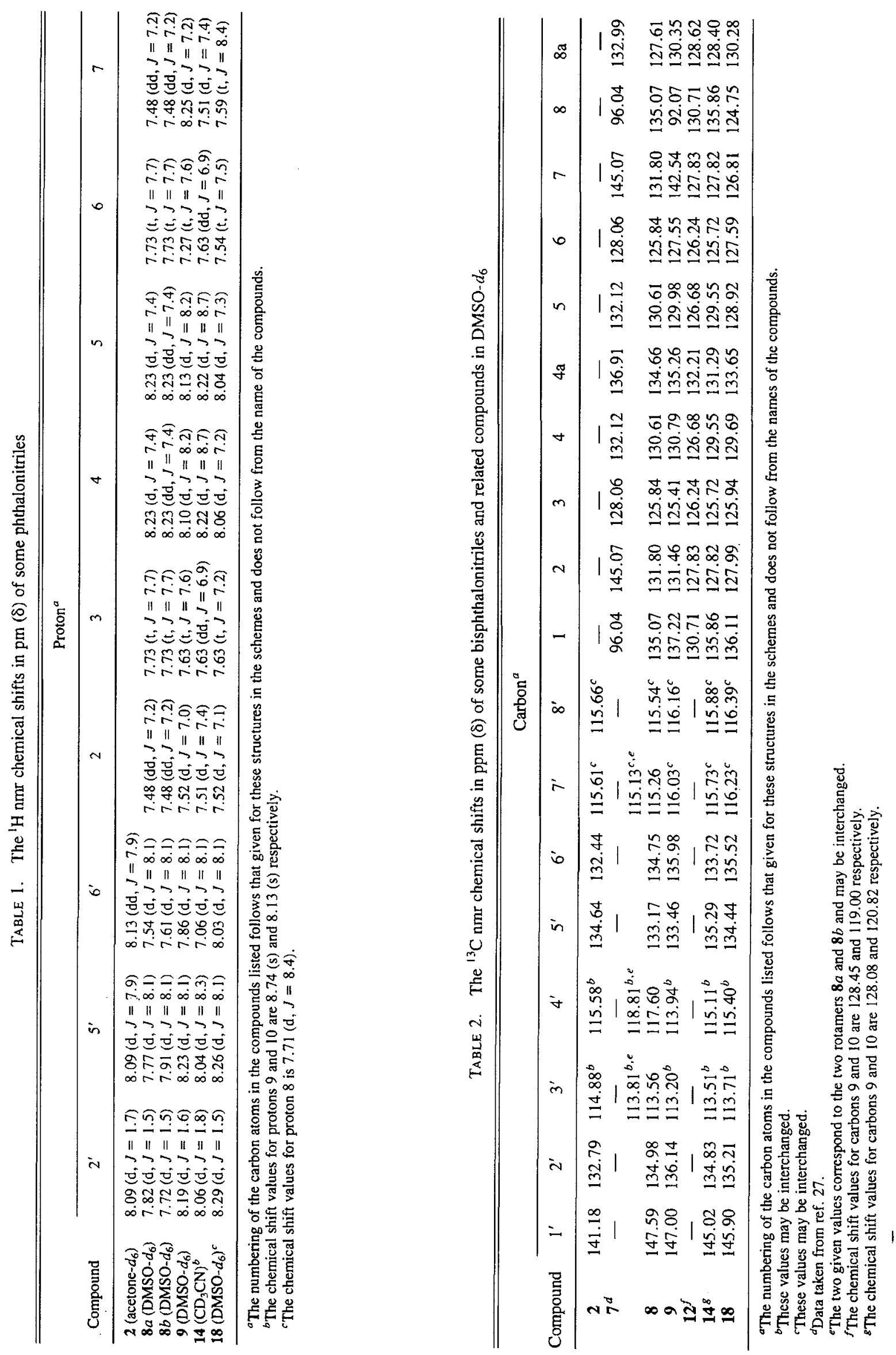


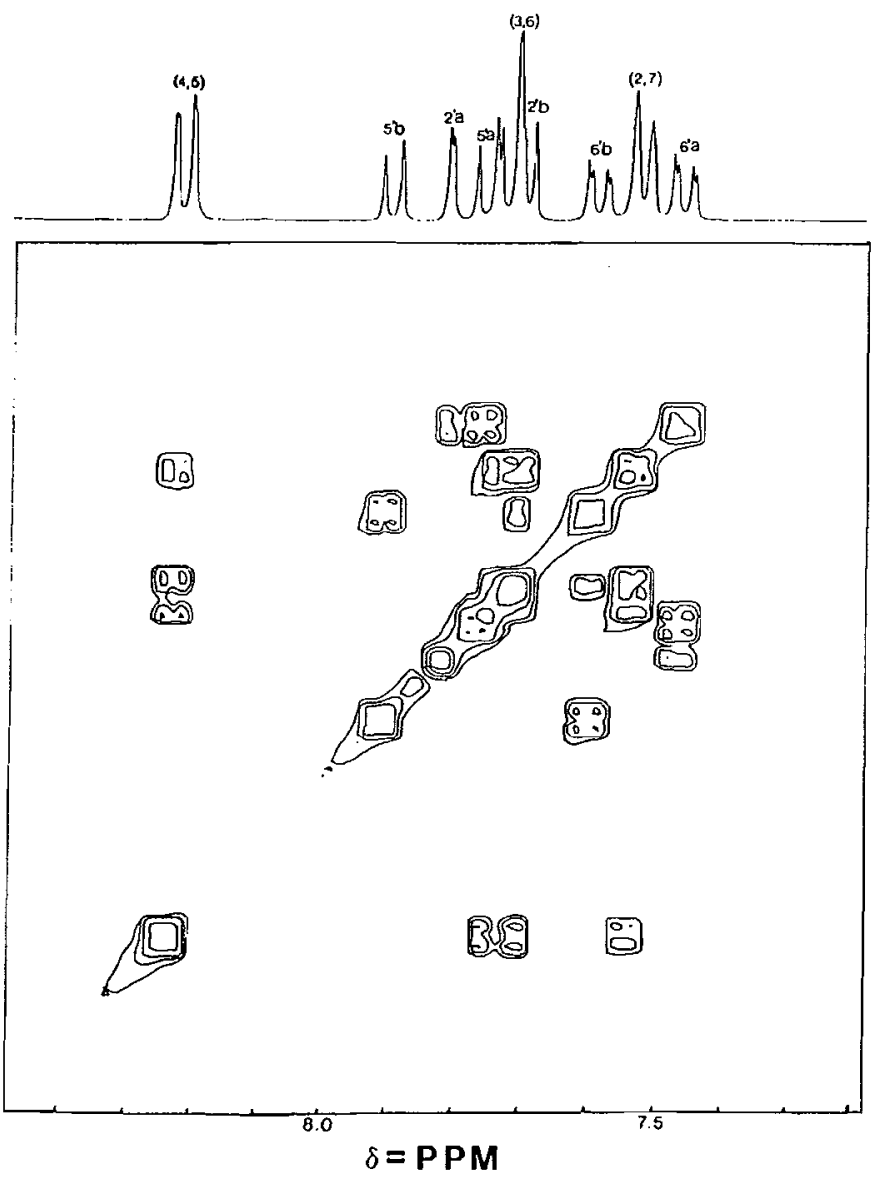

FIG. 1. ' ${ }^{1} \mathrm{H}$ homonuclear correlation (COSY) of a mixture of $8 a$ and $8 b$ in DMSO $-d_{6}$ at $25^{\circ} \mathrm{C}$.

For the 1,8-disubstituted naphthalene systems, the two parallel phenyl rings are at an angle of about $70^{\circ}$ to the plane of the naphthalene ring, to relieve some of the strain in the molecule (25). The distance between the 1,8-positions on the naphthalene ring is about $2.45 \AA(24)$, which is too small for free rotation of the 3,4-dicyano-substituted phenyl rings at room temperature. The ${ }^{1} \mathrm{H} \mathrm{nmr}$ of 8 at room temperature showed evidence that there is a sufficiently high rotation barrier between the two phenyl rings and 8 exists as two rotamers. The rotamer with two sets of cyano groups on the same side of the naphthalene plane is referred to as $8 a$ and the other rotamer with cyano groups on the opposite side is referred to as $8 \mathrm{~b}$. Proton/proton correlation experiments clearly established the coupling relationship of the protons in the rotamers. The correlation spectrum indicated the protons on the phenyl rings of $8 a$ and $8 b$ as separate systems (Fig. 1). The chemical shifts for protons on the naphthalene ring do not seem to be affected by the different orientations of the phenyl rings. A model based on the different resultant dipoles pointed in different directions for $8 a$ and $8 b$ can help to assign the chemical shifts for the protons on the phenyl rings (Fig. 2). The orientation of the resultant dipoles may influence the localization of electron density over the ring and hence the deshielding effect of the $\pi$ cloud. For $8 a$, the resultant influence is located between $\mathrm{C} 3^{\prime}$ and $\mathrm{C}^{\prime}$, which may have roughly equal effects on $\mathrm{H}^{\prime}{ }^{\prime}$ and $\mathrm{H}^{\prime}$ ' and less effect on $\mathrm{H}^{\prime}$. The expected chemical shifts are therefore $\mathrm{H} 2^{\prime}=\mathrm{H}^{\prime}>$ $\mathrm{H}^{\prime}$. For $8 b$, the resulting influence is concentrated around $\mathrm{C}^{\prime}$, affecting $\mathrm{H}^{\prime}, \mathrm{H} 2^{\prime}$, and $\mathrm{H}^{\prime}$ in decreasing order. The<smiles>Cc1ccc(-c2cccc3cccc(-c4cccc5ccccc45)c23)cc1</smiles>

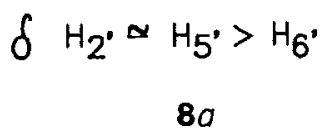

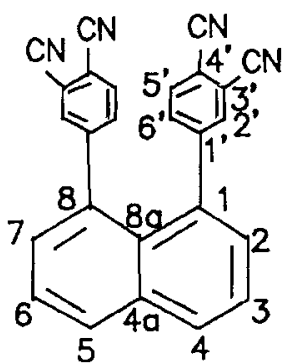

$$
\begin{gathered}
H_{5^{\prime}}>H_{2^{\prime}}>H_{6^{\prime}} \\
8 b
\end{gathered}
$$

FIG. 2. 1,8-Bis(3,4-dicyanophenyl)naphthalene rotamers $8 a$ and $8 b$.

expected chemical shifts are therefore $\mathrm{H}^{\prime}>\mathrm{H} 2^{\prime}>\mathrm{H} 6^{\prime}$. The strongest influence will be experienced by $\mathrm{H}^{\prime}$ in $8 b$ due to the close distance between $\mathrm{H}^{\prime}$ and the net dipole as shown in Fig. 2. With this model, the sequence of the predicted chemical shifts of the phenyl protons is found to be matched with the observed sequence. The nitrile groups cause the phenyl protons to shift downfield, which offsets the upfield shifting effect observed in the 1,8-diphenylnaphthalene, in which the ten phenyl protons resonate at $6.85 \mathrm{ppm}$ in carbon tetrachloride (24). A carbon $\mathrm{nmr}$ spectrum of 8 at room temperature showed 18 peaks. If only one rotamer is present, 14 peaks are expected. At $100^{\circ} \mathrm{C}$ in DMSO- $d_{6}$ the spectrum consisted of 14 peaks as expected (see Experimental).

The proton spectrum of 9 is much simpler than that of 18 even though these compounds have similar structures. The chemical shifts of $\mathrm{H}^{\prime}$ and $\mathrm{H}^{\prime}$ of 9 are more downfield shifted than $\mathrm{H6}^{\prime}$. The characteristic C-I carbon appeared at $92.07 \mathrm{ppm}$. The distance between the 1,8-positions on anthracene is about $4.8 \AA$ (16). The energy barrier of rotation of the phenyl rings at the 1,8-positions is quite small (23). In fact, ${ }^{1} \mathrm{H} \mathrm{nmr}$ and ${ }^{13} \mathrm{C}$ $\mathrm{nmr}$ of $14 \mathrm{did}$ not indicate the presence of rotamers at room temperature. Again, $\mathrm{H}^{\prime}$ and $\mathrm{H}^{\prime}$ are further downfield than $\mathrm{H6}^{\prime}$ and are consistent with the chemical shifts in the naphthalene systems.

\section{Spectroscopic properties of the phthalocyanines}

The infrared spectra of all metal-free phthalocyanines exhibited characteristic $\mathrm{NH}$ absorption at 3300 and $1020 \mathrm{~cm}^{-1}$, which disappeared upon formation of their metallated derivatives. All phthalocyanines exhibited parent ions or ion clusters in their FAB mass spectra (14). All phthalocyanines gave satisfactory $\mathrm{C}, \mathrm{H}, \mathrm{N}$ analyses, while metal analyses were also good except for $6 b$, which was slightly low.

The double $\mathrm{Q}$ band seen in the mononuclear metal-free phthalocyanines as a consequence of $D_{2 h}$ symmetry is further split due to coupling in the binuclear phthalocyanines (12). Coupling in general can be expected to occur either through space in the close cofacial conformation, or via conjugation through the unsaturated bridge, or both. For binuclear phthalocyanines with low symmetry, transitions to higher and lower energy combinations are allowed, resulting in both blue and red shifts with respect to the mononuclear species (12). In fact, the zero linked binuclear phthalocyanine $6 a$ and the previously reported 


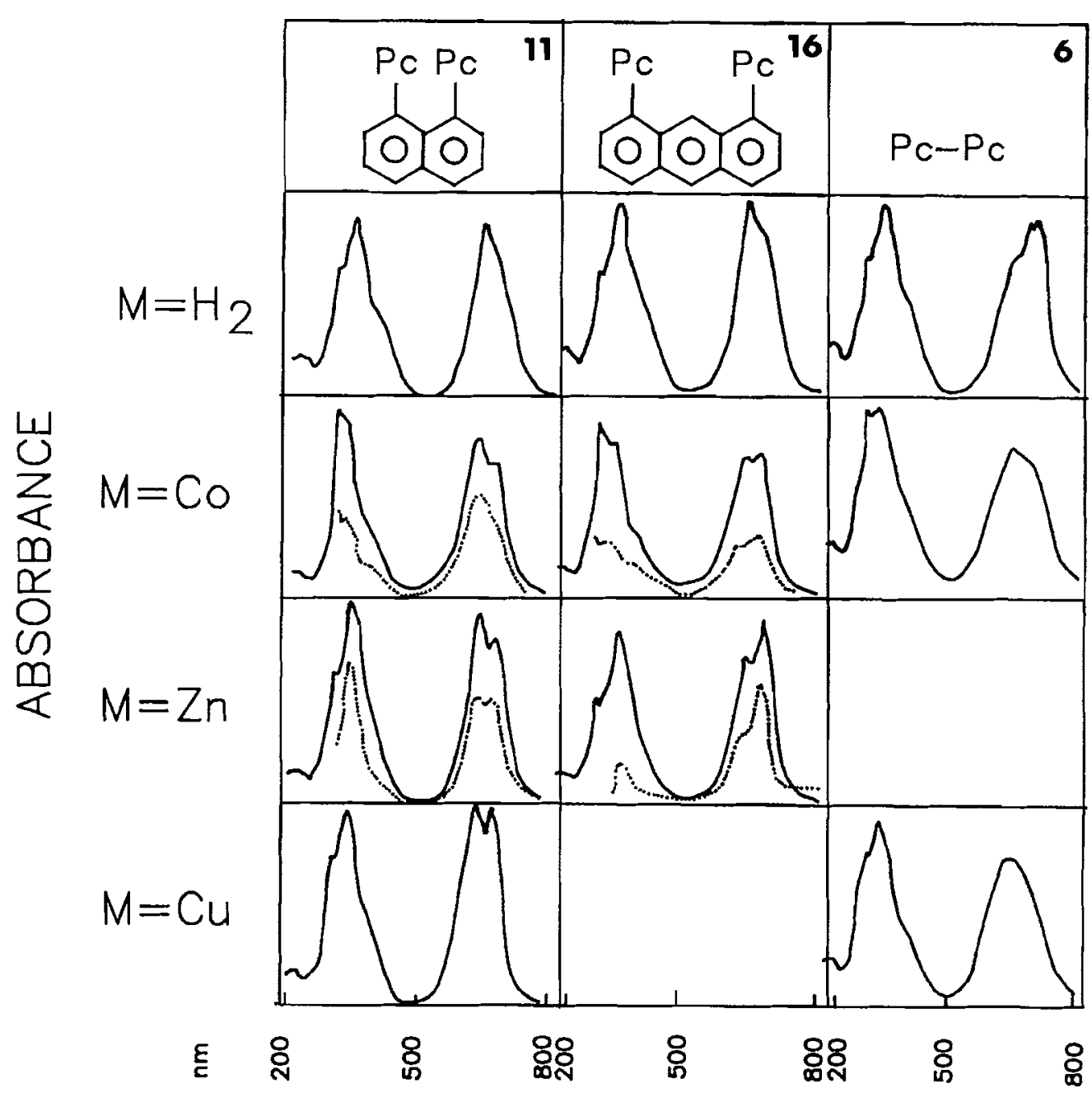

Fig. 3. Absorption spectra of metal-free and metallated binuclear phthalocyanines in o-dichlorobenzene at room temperature ([PcM], (---) $\left.\sim 1 \times 10^{-5} \mathrm{M} ;(\cdots) \sim 5 \times 10^{-7} \mathrm{M}\right)$.

binuclear phthalocyanines (4-6), except the negative linked binuclear phthalocyanine (7), show such splitting patterns. However, the electronic spectra of metal-free binuclear phthalocyanines $11 a$ and $16 a$, which closely resembled one another, exhibited a single broad $\mathrm{Q}$ band absorption at $648 \mathrm{~nm}$ but with some evidence of splitting in the spectrum of $16 a$ (Fig. 3).

Indeed, the spectra of $11 a$ and $16 a$ looked similar to the deprotonated spectrum of the five-atom bridged binuclear phthalocyanine (12), which is able to assume a close cofacial $D_{4 h}$ configuration. The similarity suggests that the two phthalocyanine rings in $11 a$ and $16 a$ are very close together and the four internal hydrogens are equivalent, which raises the symmetry of the molecules effectively to $D_{4 h}$. For phthalocyanine with $D_{4 h}$ symmetry, the $\pi-\pi^{*}$ transition is not split. There are large blue shifts in the Q band absorption in the metal-free cofacial $D_{4 h}$ binuclear phthalocyanines $11 a$ and $16 a$ (Table 3) relative to mononuclear metal-free phthalocyanines, indicative of the extensive electronic coupling between the cofacial rings $(28,29)$.

In general, all the metallated cofacial binuclear phthalocyanines showed two Q-band absorptions, the relative intensity varying with concentration. The absorption centered around $680 \mathrm{~nm}$ corresponds to the expected transition for uncoupled metallated phthalocyanines, whereas the $640-\mathrm{nm}$ transition resulted from aggregated species (30). For cofacial systems, aggregation may be both intermolecular and intramolecular. Intermolecular aggregation is expected to be concentration dependent, while intramolecular aggregation should be concentration independent. When the concentration is sufficiently reduced, the spectrum becomes concentration independent and the remaining absorption near $640 \mathrm{~nm}$ arises from intramolecular coupling (aggregation) due to the cofacial arrangement (Fig. 3).

The proton nmr spectra of the binuclear phthalocyanines exhibited absorption peaks typical of the neopentoxy group and very weak aromatic signals. The NH absorption of $6 a$ occurred around $-3 \mathrm{ppm}$. The $\mathrm{NH}$ absorption of the binuclear phthalocyanines $11 a$ and $16 a$ occurred at higher field. Binuclear phthalocyanine $11 a$ gives two sets of broad NH signals at -5 and $-6 \mathrm{ppm}$. The two sets of signals may correspond to the two configurational isomers. The isomer which is exactly cofacial is related to the bisnitrile $8 a$. The other isomer is related to bisnitrile $8 b$ in which the two rings are slightly away from each other but still have some degree of overlap in a cofacial manner. The broadening of all of the peaks is due to the positional isomers arising from the neopentyl substituents. The $\mathrm{NH}$ protons for the anthracene linked binuclear phthalocyanine $16 a$ were observed at $-6.5 \mathrm{ppm}$ and are much sharper. The sharpening of the signal may be due to increased separation between the rings so that the neopentyl groups contribute less influence 
TABLE 3. Absorption spectra of binuclear phthalocyanines in o-dichlorobenzene at room temperature $^{a}$

\begin{tabular}{|c|c|c|c|c|c|}
\hline Compound & & & $\lambda_{\max }(n m)(\varepsilon \log )$ & & \\
\hline $6 a$ & $298(4.79)$ & $342(5.94)$ & $648(4.78)$ & $682(4.89)$ & $704(4.90)$ \\
\hline $6 b$ & $300(4.90)$ & $332(4.90)$ & $652(4.79)$ & & \\
\hline $6 c$ & $300(4.76)$ & $334(4.84)$ & $642(4.74)$ & & \\
\hline $11 a$ & & $340(4.90)$ & $648(4.89)$ & & \\
\hline $11 b$ & $306(5.15)$ & & $638(5.09)$ & $674(5.01)$ & \\
\hline $11 c$ & $300(4.88)$ & $338(5.01)$ & $640(5.02)$ & $688(5.02)$ & \\
\hline $11 d$ & $298(4.88)$ & $340(5.05)$ & $640(5.03)$ & $686(4.96)$ & \\
\hline $16 a$ & & $342(5.01)$ & $646(5.00)$ & & \\
\hline $16 b$ & $298(5.03)$ & $326(4.97)$ & $640(4.94)$ & $672(4.95)$ & \\
\hline $16 c$ & $298(4.71)$ & $344(5.01)$ & $640(4.93)$ & $684(5.04)$ & \\
\hline
\end{tabular}

${ }^{a}$ The concentration of the binuclear phthalocyanines was $\sim 1 \times 10^{-5} \mathrm{M}$.

on the overall configuration and hence less variation in the orientation of the two phthalocyanine rings. The upfield shift of the internal $\mathrm{NH}$ signal is very characteristic of a cofacial configuration. It is a result of the ring current effect of the two phthalocyanine rings being held closely in a cofacial arrangement. Similar upfield shifts for NH protons in cofacial porphyrins are well documented $(2,28)$. The $\mathrm{NH}$ signal disappeared in the ${ }^{1} \mathrm{H}$ nmr spectra of the zinc derivatives of $11 a$ and $16 a$.

\section{Experimental}

Matheson high purity argon was used to maintain inert atmosphere conditions. Infrared (ir) spectra were recorded on a Pye Unicam SP 1000 infrared spectrophotometer using $\mathrm{KBr}$ discs. Nuclear magnetic resonance (nmr) spectra for protons and carbons were recorded on a Bruker AM300 nmr spectrometer. The position of signals is reported in $\delta$ units. (The splitting of the signals is described as singlets (s), doublets (d), triplets (t), quartets (q), doublets of doublets (dd), or multiplets (m).) The ${ }^{1} \mathrm{H}$ nmr spectra of $10^{-4} \mathrm{M}$ solutions of the phthalocyanines were obtained by averaging $500-3000$ scans over the absorption range. The ultraviolet-visible spectra (uv) were recurded on a Hewlett Packard HP8451A diode array spectrophotometer. Mass spectra (ms) were recorded at $70 \mathrm{eV}$ on a VG Micromass $16 \mathrm{~F}$ mass spectrometer in the EI mode. The FAB spectra were obtained with a Kratos MS-50 triple analyzer mass spectrometer equipped with a FAB ion source of standard Kratos design and Ion Tech atom gun. The sample was dissolved in chloroform and a microlitre of the resulting solution added to a microlitre of $m$-nitrobenzyl alcohol on the probe tip. The spectra of the molecular ions of the binuclear phthalocyanines were obtained by signal averaging up to 256 scans over the appropriate mass range. The number in parentheses after the indicated ion shows the percentage of the base peak represented by that ion. Melting points (mp) were determined using a Kofler hot stage melting point apparatus and are uncorrected. Flash chromatography was performed using silica gel of particle size $20-45 \mu \mathrm{m}$. All reactions, except the one that required sonication, were stirred with a magnetic stirrer. Ultrasound activation was carried out using a Branson 1200 sonicator. All solvents were freshly distilled before use. Microanalyses were performed by Guelph Chemical Laboratories Ltd., Guelph, Ontario. Thin-layer chromatography (tlc) was performed using silica gel $\mathrm{G}$ as the absorbant.

\section{$3.3^{\prime}-4,4^{\prime} \cdot$ Tetracyanobiphenyl (2)}

By a previously described method (10), nickel iodide (dried for $4 \mathrm{~h}$ at $60-70^{\circ} \mathrm{C} / 0.5 \mathrm{Torr} ; 1$ Torr $\left.=133.3 \mathrm{~Pa}\right)(4.53 \mathrm{~g}, 14.5 \mathrm{mmol})$, lithium $(0.248 \mathrm{~g}, 35.7 \mathrm{mmol})$, and naphthalene $(0.186 \mathrm{~g}, 1.45 \mathrm{mmol})$ in $30 \mathrm{~mL}$ of fresh distilled dry glyme were stirred at room temperature for $12 \mathrm{~h}$. To the nickel powder, precipitated as a bulky black slurry, was added $1.0 \mathrm{~g}(3.9 \mathrm{mmol})$ of 4-iodophthalonitrile (1) dissolved in $5 \mathrm{~mL}$ of dry glyme. The reaction mixture became warm $\left(30-35^{\circ} \mathrm{C}\right)$ and after $2 \mathrm{~h}$ the reaction was completed (tlc benzene/acetonitrile
(9:1)). The reaction mixture was poured into $100 \mathrm{~mL}$ of ice-water; the solid was filtered and washed twice with ice-water. The resulting product was washed very slowly with benzene to remove most of the naphthalene. It was then extracted with ethyl acetate, dichloromethane, and acetonitrile (three times $30-40 \mathrm{~mL}$ portions for each solvent). The ethyl acetate, dichloromethane, and acetonitrile solutions were combined and dried over $\mathrm{MgSO}_{4}$. The solvent was evaporated to give $0.5 \mathrm{~g}$ of crude product. The crude product was chromatographed by flash chromatography (11) using benzene, benzene/dichloromethane $(1: 1)$, and acetonitrile/dichloromethane $(5: 100)$ as eluants to give, in $78 \%$ yield, $0.39 \mathrm{~g}$ of 2 as white crystals, mp $291-293^{\circ} \mathrm{C}$; ir $\left(\mathrm{cm}^{-1}\right)$ : $2240(\mathrm{CN}), 1600,1480,1380,1210,910,860,840$; uv $\left(\mathrm{CH}_{2} \mathrm{Cl}_{2}\right)$ $\lambda_{\max }(\log \varepsilon): 242$ (4.16), 270 (4.18), $290(4.14 \mathrm{sh}) \mathrm{nm}$; 'H nmr and ${ }^{13} \mathrm{C}$ nmr: see Tables 1 and $2 ; \mathrm{ms} \mathrm{m} / z: 254\left(\mathrm{M}^{+}, 100\right), 227\left(\mathrm{M}^{+}-\right.$ $\mathrm{HCN}, 38), 220\left(\mathrm{M}^{+}-2 \mathrm{HCN}, 20\right)$. Anal. calcd. for $\mathrm{C}_{16} \mathrm{H}_{6} \mathrm{~N}_{4}: \mathrm{C}$ $75.60, \mathrm{H} 2.36, \mathrm{~N} 22.04$; found: C 75.54, H 2.07, N 21.98 .

\section{2,2-Bi-(9,16,23-trineopentoxyphthalocyaninyl) (6a)}

By a previously described method $(5,6)$, the two crude diiminoisoindolines 3 and 4 were obtained from $0.273 \mathrm{~g}(1.10 \mathrm{mmol})$ of 2 and $6.0 \mathrm{~g}(28 \mathrm{mmol})$ of 4-neopentoxyphthalonitrile respectively. Compounds 3 and 4 were heated at $150^{\circ} \mathrm{C}$ (oil bath) in $20 \mathrm{~mL}$ of $2-N, N$ dimethylaminoethanol and $10 \mathrm{~mL}$ of dimethylformamide (DMF) for $36 \mathrm{~h}$ under an argon atmosphere. After cooling to room temperature, the dark blue mixture was diluted with water, and the residue filtered and washed thoroughly with water until the filtrate was colorless. Preliminary purification of the product was achieved by flash chromatography using a $5 \mathrm{~cm}$ diameter column in which the crude product was preadsorbed on silica and eluted with hexane $(200 \mathrm{~mL})$, hexane/ toluene $(1: 1)(1.5 \mathrm{~L})$, and then hexane/toluene $(1: 2)$ until all the monomeric 2,9, 16,23-tetraneopentoxyphthalocyanine (5) $(3.3 \mathrm{~g}, 55 \%$ yield) was eluted. Further elution with toluene/2-methoxyethanol $(200: 5)(1.5 \mathrm{~L})$ gave, after solvent evaporation, a portion of the dimer contaminated with traces of the monomer 5 . A second portion obtained by continued elution with toluene/2-methoxyethanol (200:5) (1 L) was contaminated with some green material. The latter portion was purified by evaporating the solution to dryness; the resultant solid was suspended in dry acetone, filtered, and washed with acetone until the filtrate was colorless. Finally, the product was purified by flash chromatography using silica gel and toluene/2-methoxyethanol (200:5) as eluant to give $565 \mathrm{mg}$ ( $33 \%$ yield) of the product as a very dark blue shining solid; ir $\left(\mathrm{cm}^{-1}\right): 3300(\mathrm{NH}), 1615,1240,1100,1015(\mathrm{NH})$, 750; uv: see Table $3 ;{ }^{1} \mathrm{H}$ nmr $\delta: 3.50\left(\mathrm{br}, \mathrm{CH}_{2} \mathrm{O}\right), 1.40-1.20(\mathrm{~m}$, $\left.\left(\mathrm{CH}_{3}\right)_{3} \mathrm{C}\right) ;{ }^{13} \mathrm{C} \mathrm{nmr} \delta: 31.92,27.13,26.49 ; \mathrm{ms} \mathrm{m} / \mathrm{z}: 1543.8\left(\mathrm{M}^{+}\right)$. Anal. calcd. for $\mathrm{C}_{94} \mathrm{H}_{94} \mathrm{~N}_{16} \mathrm{O}_{6}: \mathrm{C} 73.13, \mathrm{H} 6.14, \mathrm{~N} \mathrm{14.15}$; found: $\mathrm{C}$ 73.50, H 6.39, N 14.60 .

\section{2,2-Bi-(9,16,23-trineopentoxyphthalocyaninyl) dicobalt(II) (6b)}

A mixture of $6 a(57.5 \mathrm{mg}, 0.037 \mathrm{mmol})$, anhydrous cobalt(II) chloride $(50 \mathrm{mg}, 0.38 \mathrm{mmol}), 2$-methoxyethanol $(3 \mathrm{~mL})$, and toluene $(7 \mathrm{~mL})$ was heated at $110^{\circ} \mathrm{C}$ (oil bath) for $27 \mathrm{~h}$ under an argon atmosphere. 
The product was purified by flash chromatography using a $1.5 \times 8 \mathrm{~cm}$ column by direct application of the refluxing mixture to the column. Elution with hot toluene gave, after solvent evaporation, $24 \mathrm{mg}$ of $6 \mathrm{~b}$. Continued elution with hot toluene/THF (1:1) yielded an additional $12 \mathrm{mg}$ of $6 b$. The combined $36 \mathrm{mg}$ of dimer $6 b$ was washed with acetone to remove very minor fluorescent impurities (detected by tlc), leaving $32.4 \mathrm{mg}$ ( $52 \%$ yield) of pure $6 b$ as a very dark blue solid; ir $\left(\mathrm{cm}^{-1}\right): 1615,1240,1100,750$; uv: see Table $3 ; \mathrm{ms} \mathrm{m} / \mathrm{z}: 1657.7$, $\left(\mathrm{M}^{+}\right)$. Anal. calcd. for $\mathrm{C}_{94} \mathrm{H}_{90} \mathrm{~N}_{16} \mathrm{O}_{6} \mathrm{Co}_{2}: \mathrm{C} 68.11, \mathrm{H} \mathrm{5.47,} \mathrm{N} 13.52$, Co 7.11; found: C 68.35, H 5.86, N 13.50, Co 6.40.

\section{2,2-Bi-(9,16,23-trineopentoxyphthalocyaninyl) dicopper(II) (6c)}

A mixture of $6 a(100 \mathrm{mg}, 0.065 \mathrm{mmol})$, anhydrous copper(II) acetate $(100 \mathrm{mg}, 0.550 \mathrm{mmol}), 2$-methoxyethanol $(3 \mathrm{~mL})$, and toluene $(7 \mathrm{~mL})$ was heated at $110^{\circ} \mathrm{C}$ for $24 \mathrm{~h}$ under an argon atmosphere. The solvent was removed and the mixture continuously extracted with toluene. Evaporation of toluene under reduced pressure gave $6 c(57 \mathrm{mg})$ in 53\% yield as a very dark blue shining solid; ir $\left(\mathrm{cm}^{-1}\right): 1620,1245$, 1070, 755; uv: see Table 3; $\mathrm{ms} m / z: 1667.6,\left(\mathrm{M}^{+}\right)$. Anal. caled. for

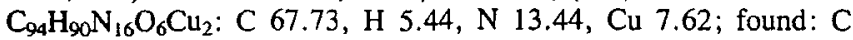
$67.72, \mathrm{H} 5.26, \mathrm{~N} 13.15, \mathrm{Cu} 7.55$.

\section{1,8-Bis(3,4-dicyanophenyl)naphthalene (8) and 1-iodo-8- \\ (3,4-dicyanophenyl)naphthalene (9)}

To $30 \mathrm{~mL}$ of freshly distilled dimethoxyethane (DME), $23.0 \mathrm{~g}$ (73 mmol) of anhydrous nickel iodide, $1.0 \mathrm{~g}(144 \mathrm{mmol})$ of lithium, and $0.8 \mathrm{~g}(6.25 \mathrm{mmol})$ of naphthalene were added. The mixture was stirred at room temperature for $12 \mathrm{~h}$. To the resulting black slurry, 4-iodophthalonitrile (1) $(4.0 \mathrm{~g}, 15 \mathrm{mmol})$ and 1,8-diiodonaphthalene (7) (25) $(2.0 \mathrm{~g}, 5.26 \mathrm{mmol})$ were added. The mixture was allowed to react for $3.5 \mathrm{~h}$. The resulting mixture was filtered through Celite using a sintered glass funnel and the residue was washed with ethyl acetate. The combined filtrate was washed with saturated sodium thiosulfate and water. The organic fraction was collected and dried over anhydrous magnesium sulphate. Evaporation of the solvent gave a yellowish brown solid. The crude material was purified by fiash chromatography using benzene as the eluting solvent to remove naphthalene and unreacted 4-iodophthalonitrile $(1.30 \mathrm{~g})$. Elution with $\mathrm{EtOAc} / \mathrm{CHCl}_{3}$ (1:9) gave $50 \mathrm{mg}$ of 1-iodo-8-(3,4-dicyanophenyl)naphthalene (9) in $2.5 \%$ yield. Recrystallization of 9 from EtOAc/hexane gave slightly brown crystals, $\mathrm{mp} 178-180^{\circ} \mathrm{C}$; ir $\left(\mathrm{cm}^{-1}\right): 3060,2240(\mathrm{CN}), 1595$, 1490, 830, 780; uv $\left(\mathrm{CH}_{2} \mathrm{Cl}_{2}\right) \lambda_{\max }(\log \mathrm{E}): 244$ (4.13), 268 (4.15), $310(4.19) \mathrm{nm} ;{ }^{1} \mathrm{H} \mathrm{nmr}$ and ${ }^{13} \mathrm{C} \mathrm{nmr}$ : see Tables 1 and 2 ; hrms, $m / z$ calcd. for $\mathrm{C}_{18} \mathrm{H}_{9} \mathrm{~N}_{2} \mathrm{I}\left(\mathrm{M}^{+}\right)$: 379.9809 ; found: 379.9802 . Anal. calcd. for $\mathrm{C}_{18} \mathrm{H}_{9} \mathrm{~N}_{2} \mathrm{I}$ : C 56.86, H 2.38, N 7.37; found: C 57.21, H 2.89, N 7.89 .

Further elution with the same solvent system gave $310 \mathrm{mg}$ of $1,8-$ bis(3,4-dicyanophenyl)naphthalene (8) in $15.5 \%$ yield. Recrystallization of 8 from EtOAc/hexane gave white crystals, mp $284-285^{\circ} \mathrm{C}$; ir $\left(\mathrm{cm}^{-1}\right): 3060,2240(\mathrm{CN}), 1600,1490,835,780 ;$ uv $\left(\mathrm{CH}_{2} \mathrm{Cl}_{2}\right) \lambda_{\max }$ $(\log \varepsilon): 238$ (4.34), $265(4.23 \mathrm{sh}), 340(4.04) \mathrm{nm} ;{ }^{1} \mathrm{H} \mathrm{nmr}$ and ${ }^{13} \mathrm{C}$ nmr: see Tables 1 and $2 ;{ }^{13} \mathrm{C}$ nmr (DMSO- $d_{6}, 100^{\circ} \mathrm{C}$ ) $\delta: 147.28$, $134.67,134.39,134.35,134.26,132.52,131.11,130.01,127.10$, $125.22,114.67,114.46,113.51,111.62 ; \mathrm{hrms}, \mathrm{m} / z$ calcd. for $\mathrm{C}_{26} \mathrm{H}_{12} \mathrm{~N}_{4}$ $\left(\mathrm{M}^{+}\right)$: 380.10619 ; found: 380.10580 . Anal. calcd. for $\mathrm{C}_{26} \mathrm{H}_{12} \mathrm{~N}_{4}: \mathrm{C}$ 82.09, H 3.18, N 14.73; found: C 82.00, H 3.34, N 14.80.

Further elution with $5 \%$ acetonitrile/dichloromethane gave $850 \mathrm{mg}$ of $\mathbf{2}$ in $42.5 \%$ yield.

\section{Preparation of the bis-1,3-diiminoisoindoline (10)}

The bis-1,3-diiminoisoindoline (10) was prepared as previously described $(5,6)$. Bisphthalonitrile $8(380 \mathrm{mg}, 1.00 \mathrm{mmol})$ was added to $20 \mathrm{~mL}$ of a 1:1 mixture of methanol/dioxane containing $15 \mathrm{mg}$ of sodium. Ammonia was bubbled into the solution at $80^{\circ} \mathrm{C}$. The reaction was over in $3 \mathrm{~h}$. The solution was evaporated to give crude 10, which was used directly in the condensation reaction without further purification.

\section{1,8-Bis-2'-(9',16',23'-trineopentoxyphthalocyaninyl)naphthalene \\ (11 a)}

The two crude diiminoisoindolines 4 and 10 obtained from $6.0 \mathrm{~g}$ $(28.00 \mathrm{mmol})$ of 4-neopentoxyphthalonitrile and $380 \mathrm{mg}(1.00 \mathrm{mmol})$ of 8 respectively, in $25 \mathrm{~mL}$ of $2-N, N$-dimethylaminoethanol, were heated to $150^{\circ} \mathrm{C}$ for $44 \mathrm{~h}$. The reaction mixture was allowed to cool and then poured into $200 \mathrm{~mL}$ of water. The resulting mixture was filtered and washed with water until the filtrate became clear. The residue was washed again with methanol and then dried overnight in the oven at $60^{\circ} \mathrm{C}$. Flash chromatography of the crude material using a $5 \mathrm{~cm}$ diameter column and eluting with toluene gave a mixture of mononuclear 5 and binuclear $11 a$. This mixture was chromatographed further using toluene/hexane (1:1) to give $2.70 \mathrm{~g}$ of 5 in $45 \%$ yield. Further elution using 2-methoxyethanol/toluene (2:100) gave a fraction consisting of mainly binuclear $11 a$. The final purification was achieved by vacuum liquid chromatography using toluene as the eluting solvent followed by gradual increase of 2-methoxyethanol/toluene (2:100) to give $139 \mathrm{mg}$ of binuclear phthalocyanine $11 a$ in $8.7 \%$ yield as a dark blue solid; ir $\left(\mathrm{cm}^{-1}\right): 3300(\mathrm{NH}), 1015,1245,1100,1020$ (NH), 750; uv: see Table $3 ;{ }^{1} \mathrm{H} \mathrm{nmr}\left(\mathrm{C}_{6} \mathrm{D}_{6}\right) 8: 7.0-8.5$ (br, aromatic), 3.3-3.8 (br, $\mathrm{CH}_{2} \mathrm{O}$ ), 1.0-1.6 (br, $\left.\left(\mathrm{CH}_{3}\right)_{3} \mathrm{C}\right),-5$ to -7 (br, $\left.\mathrm{NH}\right)$; ms $\mathrm{m} / \mathrm{z}: 1670\left(\mathrm{M}^{+}\right)$. Anal. calcd. for $\mathrm{C}_{104} \mathrm{H}_{100} \mathrm{~N}_{16} \mathrm{O}_{6}: \mathrm{C} 74.72, \mathrm{H} 6.03$, N 13.42; found: C 74.71, H 5.76, N 13.15.

\section{1,8-Bis-2'-(9',16',23'-trineopentoxyphthalocyaninyl)naphthalene dicobalt $(I I)(1 I \mathrm{~b})$}

A mixture of $33 \mathrm{mg}(0.02 \mathrm{mmol})$ of $11 \mathrm{a}$ and $60 \mathrm{mg}(0.46 \mathrm{mmol})$ of anhydrous cobalt(II) chloride in $10 \mathrm{~mL}$ of a 1:4 mixture of 2 -methoxyethanol/toluene was heated to $120^{\circ} \mathrm{C}$ for $20 \mathrm{~h}$ under an argon atmosphere. Flash chromatography of the crude reaction mixture using a $1 \mathrm{~cm}$ diameter column and eluting with 2-methoxyethanol/toluene (1:50) gave $30 \mathrm{mg}$ of $\mathbf{1 1} b$ in $85 \%$ yield as a dark blue shining solid; ir $\left(\mathrm{cm}^{-1}\right): 2940,1610,1240,1090,750$; uv: see Table $3 ; \mathrm{ms} \mathrm{m} / 2: 1782$ $\left(\mathrm{M}^{+}\right)$. Anal. calcd. for $\mathrm{C}_{104} \mathrm{H}_{96} \mathrm{~N}_{16} \mathrm{O}_{6} \mathrm{Co}_{2}: \mathrm{C} 70.00, \mathrm{H} 5.43, \mathrm{~N} 12.57$, Co 6.61; found: C 70.50, H 5.50, N 12.32, Co 6.52.

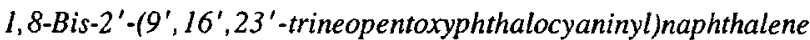 dicopper $(I I)(I 1 \mathrm{c})$}

A mixture of $53 \mathrm{mg}(0.032 \mathrm{mmol})$ of $11 \mathrm{a}$ and $57 \mathrm{mg}(0.32 \mathrm{mmol})$ of anhydrous copper(II) acetate in $10 \mathrm{~mL}$ of a 1:4 mixture of 2-methoxyethanol/toluene was heated to $120^{\circ} \mathrm{C}$ for $20 \mathrm{~h}$ under argon. The crude reaction mixture was chromatographed as described above to give $37.2 \mathrm{mg}$ of $11 \mathrm{c}$ in $70 \%$ yield as a dark blue solid; ir $\left(\mathrm{cm}^{-1}\right): 2940$, 1610, 1235, 1090, 740; uv: see Table 3; $\mathrm{ms} m / z: 1793.6\left(\mathrm{M}^{+}+1\right.$, 100). Anal. calcd. for $\mathrm{C}_{104} \mathrm{H}_{96} \mathrm{~N}_{16} \mathrm{O}_{6} \mathrm{Cu}_{2}: \mathrm{C} 69.64, \mathrm{H} 5.39, \mathrm{~N} 12.50$, $\mathrm{Cu} 7.09$; found: C 70.14, H 5.20, N 12.69, Cu 7.08.

\section{1,8-Bis-2'- $\left(9^{\prime}, 16^{\prime}, 23^{\prime}\right.$-trineopentoxyphthalocyaninyl)naphthalene $\operatorname{dizinc}(11)(11 \mathrm{~d})$}

A mixture of $50 \mathrm{mg}(0.030 \mathrm{mmol})$ of $11 a$ and $100 \mathrm{mg}(0.54 \mathrm{mmol})$ of anhydrous zinc acetate in $10 \mathrm{~mL}$ of a 1:4 mixture of 2-methoxyethanol/toluene was heated to $120^{\circ} \mathrm{C}$ for $20 \mathrm{~h}$ under argon. The crude reaction mixture was chromatographed as described for $11 b$ to give $44 \mathrm{mg}$ of $11 d$ in $86 \%$ yield as a dark blue solid; ir $\left(\mathrm{cm}^{-1}\right): 2950,1610$, 1100, 740; uv: see Table 3; ' $\mathrm{H}$ nmr $\left(\mathrm{CDCl}_{3}\right)$ 8: 7.5-8.5 (br, aromatic), 3.3-4.3 (br, $\left.\mathrm{CH}_{2} \mathrm{O}\right), 1.0-1.6\left(\mathrm{br},\left(\mathrm{CH}_{3}\right)_{3} \mathrm{C}\right)$; ms m/z: 1797.6 $\left(\mathrm{M}^{+}+1.100\right)$. Anal. calcd. for $\mathrm{C}_{104} \mathrm{H}_{96} \mathrm{~N}_{16} \mathrm{O}_{6} \mathrm{Zn}_{2}: \mathrm{C} 69.50$, H 5.38, N 12.48, Zn 7.28; found: C 69.25, H 5.73, N 12.60, Zn 7.46.

\section{1,8-Bis(3,4-dicyanophenyl)anthracene (14)}

To $60 \mathrm{~mL}$ of freshly distilled THF in a two-necked round-bottom flask, $2.0 \mathrm{~g}(8.1 \mathrm{mmol})$ of 1,8-dichloroanthracene (12) and $5.49 \mathrm{~g}$ (24 mmol) of anhydrous zinc bromide were added. The solution was cooled to $0^{\circ} \mathrm{C}$. With a strong stream of argon flowing through the flask, $0.24 \mathrm{~g}$ ( $36 \mathrm{mmol}$ ) of lithium wire was cut into small pieces and dropped into the solution. The mixture was sonicated with ultrasound at $0^{\circ} \mathrm{C}$ for $1 \mathrm{~h}$ under argon and allowed to warm up to room temperature. The dark solution containing the zinc organometallic intermediate 13 was transferred with a syringe to another round-bottom flask containing $4.0 \mathrm{~g}(16 \mathrm{mmol})$ of 1 and $0.8 \mathrm{~g}$ ( $4 \mathrm{~mol} \%$ ) tetrakis(triphenylphosphine)palladium. The resulting solution was stirred under argon at room temperature for $3 \mathrm{~h}$. Ethyl acetate and water were added to the reaction mixture, and the cloudy mixture was filtered through Celite. The filtrate separated into an aqueous and an organic layer. The organic 
layer was collected and dried over anhydrous $\mathrm{MgSO}_{4}$. Evaporation of the solvent gave a brownish crude material. The crude material was purified by flash chromatography using chloroform as the eluting solvent. The first fraction contained mostly unreacted starting material. Further elution gave $34.5 \mathrm{mg}$ of 1,8-bis(3,4-dicyanophenyl)anthracene (14) in $10 \%$ yield. Recrystallization of 14 from acetonitrile/EtOAc gave yellow crystals, $\mathrm{mp} 345-346^{\circ} \mathrm{C}$; ir $\left(\mathrm{cm}^{-1}\right): 3060,2230(\mathrm{CN})$, $1590 ; 1490,880,745$; uv $\left(\mathrm{CH}_{2} \mathrm{Cl}_{2}\right) \lambda_{\max }(\log \varepsilon): 284$ (4.05), 268 (4.06), 386 (3.99), 405 (3.96); ${ }^{1} \mathrm{H} \mathrm{nmr}$ and ${ }^{13} \mathrm{C} \mathrm{nmr}$ : see Tables 1 and 2; ms $m / z: 430\left(\mathrm{M}^{+}, 100\right) 330(20)$. Anal. calcd. for $\mathrm{C}_{30} \mathrm{H}_{14} \mathrm{~N}_{4}: \mathrm{C}$ 83.69, H 3.28, N 13.02; found: C 83.42, H 3.46, N 13.15.

\section{Preparation of the bis-1,3-diiminoisoindoline (15)}

Bisphthalonitrile $14(430 \mathrm{mg}, 1.0 \mathrm{mmol})$ was added to $50 \mathrm{~mL}$ of a $1: 1$ mixture of methanol/dioxane containing $15 \mathrm{mg}$ of sodium. Ammonia was bubbled into the solution under reflux at $80^{\circ} \mathrm{C}$ for $2 \mathrm{~h}$. The solution was evaporated to give the crude bis-1,3-diiminoisoindoline (15), which was used directly in the condensation reaction without further purification.

\section{I, 8-Bis-2' $-\left(9^{\prime}, 16^{\prime}, 23^{\prime}\right.$-trineopentoxyphthalocyaninyl)anthracene} (16a)

The two crude diiminoisoindolines 15 and $4(5,6)$, obtained from $430 \mathrm{mg}(1.0 \mathrm{mmol})$ of 14 and $6.0 \mathrm{~g}(28.0 \mathrm{mmol})$ of 4-neopentoxyphthalonitrile respectively in $25 \mathrm{~mL}$ of $2-N, N$-dimethylaminoethanol, were heated to $160^{\circ} \mathrm{C}$ for $44 \mathrm{~h}$. The reaction mixture was allowed to cool and then poured into $200 \mathrm{~mL}$ of water. The resulting mixture was filtered and washed with water until the filtrate became clear. The residue was washed again with $\mathrm{MeOH}$ and then dried in the oven at $60^{\circ} \mathrm{C}$ overnight. Flash chromatography of the crude material using toluene as eluting solvent gave a mixture of mononuclear 5 and binuclear 16a. Rechromatography of the mixture using toluene/hexane (1:1) did not give a good separation. The binuclear fractions were still contaminated with large amounts of 5 . The mixed binuclear fraction was rechromatographed using a gel permeation column (Bio-Beads SX-1, 200-450 mesh) with THF as the eluting solvent. The front running binuclear fractions were combined and rechromatographed on a silica gel column using 2-methoxyethanol/toluene $(2: 100)$ as the eluting solvent to give $210 \mathrm{mg}$ of 1,8 -bis- $2^{\prime}-\left\{9^{\prime}, 16^{\prime}, 23^{\prime}\right.$-trineopentoxyphthalocyaninyl)anthracene (16a) in $12 \%$ yield as a dark blue solid; ir $\left(\mathrm{cm}^{-1}\right): 3300(\mathrm{NH}), 1610,1240,1100,1020(\mathrm{NH}), 750$; uv: see Table 3; ${ }^{1} \mathrm{H}$ nmr $\left(\mathrm{C}_{6} \mathrm{D}_{6}\right)$ 8: 7.0-8.5 (br, aromatic), 3.5-3.7 (br, $\left.\mathrm{CH}_{2} \mathrm{O}\right), 1.0-1.6\left(\mathrm{br},\left(\mathrm{CH}_{3}\right)_{3} \mathrm{C}\right),-6$ to $-7(\mathrm{NH}) ; \mathrm{ms} \mathrm{m} / \mathrm{z}: 1719\left(\mathrm{M}^{+}\right.$, $100 \%$ ). Anal. calcd. for $\mathrm{C}_{108} \mathrm{H}_{102} \mathrm{~N}_{16} \mathrm{O}_{6}:$ C 75.39, H 5.98, N 13.03; found: C 75.18, H 6.33, N 12.65.

\section{1,8-Bis-2'-(9',16',23'-trineopentoxyphthalocyaninyl)anthracene dicobalt(II) (16b)}

A mixture of $52 \mathrm{mg}(0.030 \mathrm{mmol})$ of $16 a$ and $60 \mathrm{mg}(8.46 \mathrm{mmol})$ of anhydrous cobalt(II) chloride in $10 \mathrm{~mL}$ of a 1:4 mixture of 2-methoxyethanol/toluene was heated to $120^{\circ} \mathrm{C}$ for $20 \mathrm{~h}$. The crude reaction mixture was flash chromatographed using 2-methoxyethanol/toluene (1:80) and gave $56 \mathrm{mg}$ of $16 \mathrm{~b}$ in $95 \%$ yield; ir $\left(\mathrm{cm}^{-1}\right): 2940,1610$, 1240, 1090, 750; uv: see Table 3; ms m/z: $1832\left(\mathrm{M}^{+}\right)$. Anal. calcd. for $\mathrm{C}_{108} \mathrm{H}_{98} \mathrm{~N}_{16} \mathrm{O}_{6} \mathrm{Co}_{2}$ : C 70.71, H 5.38, N 12.23, Cu 6.43; found: $\mathrm{C}$ $70.90, \mathrm{H} 5.88, \mathrm{~N} 11.83$, Co 6.40 .

\section{1,8-Bis-2'- $\left(9^{\prime}, 16^{\prime}, 23^{\prime}\right.$-trineopentoxyphthalocyaninyl)anthracene $\operatorname{dizinc}(I I)(16 \mathrm{c})$}

A mixture of $56 \mathrm{mg}(0.0325 \mathrm{mmol})$ of $16 a$ and $100 \mathrm{mg}(0.54 \mathrm{mmol})$ of anhydrous zinc acetate in $10 \mathrm{~mL}$ of a 1:4 mixture of 2-methoxyethanol/toluene was heated to $120^{\circ} \mathrm{C}$ for $20 \mathrm{~h}$. The crude reaction mixture was flash chromatographed using 2-methoxyethanol/toluene (1:50) to give $58 \mathrm{mg}$ of $16 \mathrm{c}$ in $97 \%$ yield; ir $\left(\mathrm{cm}^{-1}\right): 2950,1610$, 1240, 1090, 750; uv: see Table $3 ;{ }^{1} \mathrm{H}$ nmr $\left(\mathrm{C}_{6} \mathrm{D}_{6}\right)$ 8: 7.5-8.5 (br, aromatic), 3.3-4.3 (br, $\left.\mathrm{CH}_{2} \mathrm{O}\right), 1.0-1.6\left(\mathrm{br},\left(\mathrm{CH}_{3}\right)_{3} \mathrm{C}\right) ; \mathrm{ms} \mathrm{m} / \mathrm{z}$ : $1847\left(\mathrm{M}^{+}\right)$. Anal. calcd. for $\mathrm{C}_{108} \mathrm{H}_{98} \mathrm{~N}_{10} \mathrm{O}_{6} \mathrm{Zn}_{2}: \mathrm{C} 70.22, \mathrm{H} 5.35, \mathrm{~N}$ 12.14, $\mathrm{Zn} 7.08$; found: C 70.72, H 5.65, N 11.60, Zn 7.45.

\section{I-(3,4-Dicyanophenyl)naphthalene (18)}

Following a previously described procedure $(17,18), 1.0 \mathrm{~g}(2.63$ mmol) of 1.8-diiodonaphthalene and $1.78 \mathrm{~g}(7.9 \mathrm{mmol})$ of anhydrous zinc bromide were added to a two-necked flask containing $60 \mathrm{~mL}$ of freshly distilled THF. The solution was cooled to $0^{\circ} \mathrm{C}$. Lithium $(0.09 \mathrm{~g}$, $0.013 \mathrm{mmol}$ ) was cut into small pieces and added into a flask flushed with a vigorous stream of argon. The mixture was sonicated with ultrasound at $0^{\circ} \mathrm{C}$ for $1 \mathrm{~h}$ under argon and allowed to warm to room temperature. The resulting solution was transferred with a syringe to another round-bottom flask containing $1.33 \mathrm{~g}(5.26 \mathrm{mmol})$ of $\mathbf{1}$ and $0.8 \mathrm{~g}(\sim 4 \mathrm{~mol} \%)$ tetrakis(triphenylphosphine)palladium. After stirring this mixture at room temperature for $3 \mathrm{~h}$, water was added, followed by ethyl acetate. The cloudy mixture was filtered through Celite. The filtrate separated into aqueous and organic layers. The organic layer was collected and dried over anhydrous $\mathrm{MgSO}_{4}$. Evaporation of the solvents gave a brownish colored crude material. The crude material was purified by flash chromatography using chloroform. The first fraction contained mostly starting material. Further elution gave $200 \mathrm{mg}$ of 18 in $30 \%$ yield as white crystals, mp $148-149^{\circ} \mathrm{C}$; ir $\left(\mathrm{cm}^{-1}\right): 3060$, $2230(\mathrm{CN}), 1600,1485,1390,910,770$; uv $\left(\mathrm{CH}_{2} \mathrm{Cl}_{2}\right) \lambda_{\max }(\log \varepsilon)$ : 242 (3.67), $282(3.42), 324(3.41) \mathrm{nm}$; ' $\mathrm{H} \mathrm{nmr}$ and ${ }^{13} \mathrm{C} \mathrm{nmr}$ : see Tables 1 and $2 ; \mathrm{ms} \mathrm{m} / 2: 254\left(\mathrm{M}^{+}\right)(100 \%), 233$ (15\%). Anal. calcd. for $\mathrm{C}_{18} \mathrm{H}_{10} \mathrm{~N}_{2}: \mathrm{C} 83.69, \mathrm{H} \mathrm{3.28}, \mathrm{N}$ 13.02; found: $\mathrm{C} 83.42, \mathrm{H} \mathrm{3.46,N}$ 13.15.

\section{Acknowledgements}

Financial support by the Natural Sciences and Engineering Research Council of Canada and by The Office of Naval Research (Washington) is gratefully acknowledged. We would like to thank Mr. Byron Bachelor for his assistance in the preparation of compound 2 . The work was also funded by the Midwest Center for Mass Spectrometry, a National Science Foundation Regional Instrumentation Facility (Grant No. CHE8620177).

1. D. LeXa, P. Millard, M. Momenteau, and J. M. Saveant. J. Am. Chem. Soc. 106, 6321 (1984); P. Sayer, M. Gouterman, and C. R. ConNell. Acc. Chem. Res. 15, 73 (1982); P. ForSwey, T. Kuwana, N. Kobayashi, and T. Osa. Adv. Chem. Ser. 201, 601 (1982); J. ZaGal, P. Binora, and E. Yeager. J. Electrochem. Soc. 127, 1506 (1980); F. VAN DEN BRINK, E. Barendrecht, and W. Visscher. Recl. Trav. Chim. Pays-Bas, 99, 253 (1980); K. Kasuea, and M. Tsutsui. Coord. Chem. Rev. 32, 67 (1980).

2. J. P. Collman, P. Denisevich, Y. Konal, M. Marrocco, C. Koval, and F. C. Anson. J. Am. Chem. Soc. 102, 6027 (1980) J. P. Collman, F. C. Anson, S. Bencosme, A. Chong, T. Collins, P. Denisevich, E. Evitt, T. Geiger, J. A. Igers, G. Jameson, Y. Konal, C. Koval, K. MeIER, P. OAKLEY, R. B. Pettman, E. Schmitrou, and J. Sessler. In Organic synthesis today and tomorrow. Edited by B. M. Trost and C. R. Hutchinson. Pergamon, Oxford. 1981; R. R. Durand, C. S. Bencosme, J. P. Collman, and F. C. Anson. J. Am. Chem. Soc. 105, 2710 (1983); J. P. Collman, F. C. Anson, C. E. Barnes, C. S. Bencosme, T. Geiger, E. R. Evitt, R. P. Kreh, K. Meier, and R. B. Petrman. J. Am. Chem. Soc. 105, 2694 (1983).

3. C. K. Chang and I. Abdalmuhdi. J. Org. Chem. 48, 5388 (1983); C. K. Chang, H. Y. LiU, and I. Abdalmuhdi. J. Am. Chem. Soc. 106, 2725 (1984); C. K. Chang and I. AbdalMUHDI. Angew. Chem. 23, 164 (1984); H. Y. LiU, I. ABDALMUHdi, C. K. Chang, and F. C. Anson. J. Phys. Chem. 89, 665 (1985); J. P. Fillers, K. G. Ravichandran, I. AbdalMuhdi, A. Tulinsky, and C. K. Chang. J. Am. Chem. Soc. 108, 417 (1986).

4. S. Greenberg, S. M. Marcuccio, C. C. Leznoff, and K. B. TOMER. Synthesis, 406 (1986).

5. S. M. Marcuccio, P. I. Svirskaya, S. Greenberg, A. B. P. Lever, C. C. Leznoff, and K. B. Tomer. Can. J. Chem. 63, 3057 (1985).

6. C. C. Leznoff, S. Greenberg, S. M. Marcuccio, P. C. Minor, P. Seymour, A. B. P. Lever, and K. B. Tomer. Inorg. 
Chem. Acta, 89, L35 (1984); C. C. Leznoff, S. M. Marcuccio, S. Greenderg, A. B. P. Lever, and K. B. Tomer. Can. J. Chem. 63, 623 (1985).

7. C. C. Leznoff, H. Lam, S. M. Marcuccio, W. A. Nevin, P. Janda, N. Kobayashi, and A. B. P. Lever. J. Chem. Soc. Chem. Commun. 699 (1987)

8. M. R. Hempstead, A. B. P. Lever, and C. C. Leznoff. Can. J. Chem. 65, 2677 (1987)

9. C. C. Leznoff, H. Lam, W. A. Nevin, N. Kobayashi, P. Janda, and A. B. P. Lever. Angew. Chem. Int. Ed. Engl. 26, 1021 (1987).

10. S. Inaba, H. Matsumoto, and R. D. Rieke. Tetrahedron Lett. 23, 4215 (1982); H. MATSUMOTO, S. INABA, and R. D. RJEKE. J. Org. Chem. 48, 840 (1983); S. Inaba, H. Matsumoto, and R. D. RiEkE. J. Org. Chem. 49, 2093 (1984).

11. W. C. Still, M. KaHN, and A. Mitra. J. Org. Chem. 43, 2923 (1978)

12. E. S. Dodsworth, A. B. P. Lever, P. Seymour, and C. C. LEzNoff. J. Phys. Chem. 89, 5698 (1985).

13. N. M. Targett, J. P. Kilcoyne, and B. Green. J. Org, Chem. 44, 4962 (1979).

14. M. BARBER, R. S. Bordoli, R. D. SEDGWICK, and A. N. Tyler. J. Chem. Soc. Chem. Commun. 325 (1981).

15. H. O. House, W. J. Campbell, and M. Gall. J. Org. Chem. 35, 1815 (1970).

16. H. O. House, D. Koepsell, and W. Jaeger. J. Org. Chem. 38 , 1167 (1973).

17. E. Negishi. Acc. Chem. Res. 15, 340 (1982); E. Negishi. In Current trends in organic synthesis. Pergamon Press, Oxford. 1982. p. 269.

18. E. Negishi, A. O. King, and N. OKukdo. J. Org. Chem. 42 , 1821 (1977); T. R. BAILEY. Tetrahedron Lett. 27, 4407 (1986).
19. B. J. WAKEFELD. In The chemistry of organolithium compounds. Pergamon Press, Oxford. 1974. p. 247.

20. J. L. Luche, C. Petrier, J. P. Lansard, and A. E. Greene. J. Org. Chem. 48, 3837 (1983).

21. C. Petrier, J. C. de Souza Barbosa, C. Dupuy, and J. L. Luche. J. Org. Chem. 50, 5761 (1985); P. Boudjouk, R. Sooriyakumaran, and B. H. HaN. J. Org. Chem. 51, 2818 (1986); D. Bremner. Chem. Br. 633 (1986); T. J. Mason. Educ. Chem. 102 (1987).

22. J. A. Anton, J. Kwong, and P. A. Loach. J. Heterocycl. Chem. 13, 717 (1976); W. A. Nevin, W. LiU, S. GREENBERG, M. R. Hempstead, S. M. Marcuccio, M. Melnik, C. C. Lez NOFF, and A. B. P. Lever. Inorg. Chem, 26, 891 (1987).

23. H. O. House, J. A. Hrabie, and D. VanDerveer. J. Org. Chem. 51, 921 (1986).

24. H. O. House, R. W. Magin, and H. W. Thompson. J. Org Chem. 28, 2403 (1963); V. BalasubramaniYan. Chem. Rev. 66, 567 (1966).

25. H. O. House, D. G. Koepsell, and W. J. Campbell. J. Org. Chem. 37, 1003 (1972).

26. J. D. MEMORY and N. K. WILSON. In NMR of aromatic compounds. John Wiley \& Sons, New York. 1982. p. 78; F. TODA, T. OSHIMA, Y. IshidA, Y. TAKEHIRA, K. SaIto, and K. TANAKa In Handbook of ${ }^{13} \mathrm{C}$ NMR spectra. Sankyo, Japan. 1981.

27. P. E. Hansen. Org. Magn. Reson. 12, 109 (1979); B. P. Сно and R. G. Harvey. J. Org. Chem. 52, 5679 (1987).

28. D. Dolphin, J. Hiom, and J. B. PaIne II. Heterocycles, 16, 417 (1981).

29. C. K. Chang. J. Chem. Soc. Chem. Commun. 800 (1977).

30. W. A. Nevin, W. LiU, and A. B. P. Lever. Can. J. Chem. 65, 855 (1987). 